\title{
University-enterprise Cooperation Practical Teaching Evaluation Model for polytechnic based on AHP and Fuzzy
}

\author{
Wuxue Jiang ${ }^{1}$, Pei Chai ${ }^{2}$, Yuqiang Chen ${ }^{1}$, Shi Wang ${ }^{1}$ \\ ${ }^{1}$ Department of Computer Engineering, Dongguan Polytechnic, Dongguan, 523808, China \\ ${ }^{2}$ Division of Science Research, Guangdong Polytechnic Normal Universtiy, 510665, China \\ ${ }^{3}$ Department of Art and Design, Dongguan Polytechnic, Dongguan, 523808, China
}

Keywords: AHP, Fuzzy, Teaching evaluation model, Polytechnic practice teaching, Conformance test, University-enterprise cooperation.

\begin{abstract}
In order to conduct an effective evaluation of the vocational school-enterprise cooperation practical education, this article constructs a vocational students' graduation design evaluation index system based on the university-enterprise cooperation, which regards the vocational graduation design as vector and the experience as foundation. According to the AHP, this article has educed the right weight ratio of the primary and secondary index and applies the consistency check to the reasonableness of the weights for verification. Combined with comprehensive fuzzy theory, the article builds the evaluation findings, processes the questionnaire data in accordance with the fuzzy decision-making process and makes the appropriate conclusions. Case shows that the evaluation system is available to proceeding effectively evaluation of the university-enterprise cooperation graduation design practical teaching effectiveness and has good maneuverability.
\end{abstract}

\section{Introduction}

Teaching quality evaluation of teacher is the important constitution and content of university teaching quality management. The existing study on the classroom teaching quality evaluation mainly focuses on four aspects: First, study on the evaluation means or methods, second, study on the subject of the evaluation, third, study on the content of the evaluation study, fourth, study on the evaluation index. The vocational education is skills-based education with particular emphasis on practical teaching. Currently, the study on evaluation of vocational practice teaching has become a hot spot. The university-enterprise cooperation is one of the main training modes of higher vocational education. The students' graduate design from some institutions have been directed by universities and businesses jointly, such as university-enterprise cooperation topics, universityenterprise cooperation to guide the design process, enterprises to participate in graduation reply process and university-enterprise to conduct evaluation of graduation design jointly etc. Because of the participation of the enterprises, it has increased the difficulty of the evaluation of graduation design teaching.

\section{Analysis Hierarchy Process}

Analytic Hierarchy Process, referred to as AHP, is a decision-making way to conduct qualitative and quantitative analysis based on broking down the elements related to the decision-making into the objectives, tasks and indicators etc. AHP has been widely used and it could be applied to evaluate the priorities of objectives or the weight ratio of the evaluation index in the field of education.

Application Process of AHP. Establish a hierarchical model. The uppermost factor is the ultimate goal. In the lower layer of the ultimate goal, determine that if the various factors have relationship with the upper layer of factors according to the decision maker's subjective judgment [1]. In general, in addition to the uppermost factor, the amount of each layer factors could be up to seven. The 
number of layers could be set according to the structural problems and there is no limit of the layer number, the lowest layer is the program to be selected.

Construct pair wise comparison judgment matrix. Compare the factors of one layer with various factors of the upper layer in pair, if there are $n$ factors involved in the comparison, conduct $n(n-1) / 2$ times of pair wise comparison. Pairwise comparison of the resulting value generally could be taken from $1 / 9,1 / 8, \ldots, 1 / 2,1,2, \ldots, 8,9$ and so on.

Calculate the weight ratio of the factors of each layer and derive decision scheme. Calculate the weight ratio of the programs to be selected on the uppermost factor. By comparing the derived weights, determine that which decision-making scheme is feasible finally.

Conformance test. Judge the eigenvector $\mathrm{W}$ of the matrix A corresponding to the maximum eigenvalue $^{\lambda_{\max }}$, after normalization, obtain the order weight value of relative importance between several corresponding factors of the same layer and some factor of the upper layer.

$$
C I=\frac{\lambda_{\max }-n}{m-1}
$$

\section{Fuzzy Comprehensive Evaluation}

Fuzzy comprehensive evaluation method is a scientific evaluation methods proposed by American cybernetics expert Zadeh, who uses the basic theories and methods of fuzzy mathematics to quantify the fuzzy and uncertain things in the real world widespread, so as to make a relatively objective, accurate and realistic evaluation to solve practical problems [2][3]. The basic principle is to gather information of preparing teaching evaluation projects and to determine the evaluation factors and evaluation rating in the first phase. In the second phase, construct FUZZY mathematical model according to the weight ratio of evaluation index educed with the method of AHP. If the weight ratio educed with AHP method is $\omega_{i}(i=1,2, \cdots, m)$, assuming that the evaluation equivalence domain is $A=\left(a_{1}, a_{2}, \cdots, a_{n}\right)$, then construct fuzzy matrix $\mathrm{R}$ with grade domain and fuzzy relationship that takes influence on the factors [4].

$$
R=\left[\begin{array}{cccc}
r_{11} & r_{12} & \cdots & r_{1 m} \\
r_{21} & r_{22} & \cdots & r_{2 m} \\
\vdots & \vdots & \cdots & \vdots \\
r_{m 1} & r_{m 2} & \cdots & r_{m m}
\end{array}\right]
$$

Then take the fuzzy evaluation matrix and evaluation index weight ratio $\omega_{i}(i=1,2, \cdots, m)$ into $B=\omega \circ R$ for calculation, conduct the normalization process for the results and finally obtain the evaluation result according to the maximum membership principle or downgrade accumulation over half principle.

\section{Fuzzy Comprehensive Evaluation Steps}

1) Establish the factor set of evaluation objects, U, and divide the evaluation factors into several levels.

2) Establish the comment set of evaluation factors.

3) Determine the weight ratio of each evaluation factor. Because of the different importance of each factor in the comprehensive evaluation, it is necessary to give each factor an appropriate weight coefficient. Assume that the weight of evaluation factors are respectively $a_{1}, a_{2}, \cdots, a_{m}$ obtain the fuzzy $\operatorname{set} A=\left(a_{1}, a_{2}, \cdots, a_{m}\right)$, and $\sum_{i=1}^{m} a_{i}=1$.

4) Establish the comprehensive evaluation matrix R. For each evaluation object, there is need to establish a comprehensive evaluation matrix R. And $R_{i}=\left(r_{i 1}, r_{i 2}, \cdots, r_{i n}\right)$ is the single factor that the i- 
th factor $u_{i}$ is in the comment set $\mathrm{V}$ [5][6]. The $r_{i j}$ represents the membership that the $\mathrm{i}$-th factor obtains j-th comment $v_{j}$, which must meet $\sum r_{i j}=1$ after the normalization generally.

5) Fuzzy comprehensive evaluation. According to the comprehensive evaluation matrix and weight set, the comprehensive evaluation result of the object is fuzzy set: $B=\omega \circ R=\left(b_{1}, b_{2}, \cdots, b_{n}\right)$. And conduct normalization process for B.

6) Calculate comprehensive evaluation scores. In order to obtain visual score presentation of the evaluation result, it is allowed to conduct assignment to the comment level and the assignment matrix is $G=\left(G_{1}, G_{2}, \cdots, G_{n}\right)$, so the evaluation result presented in the form of score value is $Y=B \cdot G^{T}=\left(b_{1}, b_{2}, \cdots, b_{n}\right) \cdot\left(G_{1}, G_{2}, \cdots, G_{n}\right)^{T}$. And $\mathrm{Y}$ is just the comprehensive evaluation score of the object.

\section{Vocational Graduation Design Evaluation Index System}

Vocational graduation design is an important part of evaluating the student skills, the evaluation of graduation project is divided into three indicators, the first-level indicator includes the design topics, design organization and guidance, thesis plea, and design effects.

According to the general practice of teacher evaluation, the evaluation classification of each index includes four levels, namely "excellent", "good", "pass" and "fail", and each level corresponds to the set score: 95, 85, 65 and 45. Therefore comment set V=\{"excellent", "good", "pass", "fail"\}, which corresponds to comment score set $\mathrm{G}=(95,85,65,45)$.

Construct the first-level index judgment matrix, as shown in Table 1.

Table 1: The First-level Index Judgment Matrix

\begin{tabular}{l|c|c|c|c}
\hline & $\begin{array}{c}\text { Design } \\
\text { topics }\end{array}$ & $\begin{array}{c}\text { organization and } \\
\text { guidance }\end{array}$ & Thesis plea & $\begin{array}{c}\text { Design } \\
\text { effectiveness }\end{array}$ \\
\hline Design topics & 1 & $1 / 2$ & $1 / 3$ & 1 \\
\hline $\begin{array}{l}\text { organization and } \\
\text { guidance }\end{array}$ & 2 & 1 & $1 / 2$ & 2 \\
\hline $\begin{array}{l}\text { Thesis plea } \\
\text { Design }\end{array}$ & 3 & 2 & 1 & 3 \\
\hline
\end{tabular}

Conduct normalization and summation of each row sum. After renormalization, an eigenvector is obtained, namely $W=(0.14,0.26,0.46,0.14)$, calculate the maximum eigenvalue $\lambda_{\max }=4.004$, according to $C I=\frac{\lambda_{\max }-n}{m-1}$ and $C R=\frac{C I}{R I}$, it could be calculated that $C R=0.0018<0.10$, which is believed that the comparison matrix has satisfactory consistency, so the weight coefficient of the first-level indicator is shown in Table 2.

Table 2: The First-level Index Weight Table of Vocational Graduation Design Evaluation Index System

\begin{tabular}{l|c|c|c|c}
\hline $\begin{array}{l}\text { The first-level } \\
\text { indicator }\end{array}$ & $\begin{array}{c}\text { Design } \\
\text { topics }\end{array}$ & $\begin{array}{c}\text { organization } \\
\text { and guidance }\end{array}$ & $\begin{array}{c}\text { Thesis } \\
\text { plea }\end{array}$ & $\begin{array}{c}\text { Design } \\
\text { effectiveness }\end{array}$ \\
\hline Weight & 0.14 & 0.26 & 0.46 & 0.14 \\
\hline
\end{tabular}

\section{Fuzzy Decision Strategies}

1) Summarize the questionnaire data. 2) Calculate the comprehensive evaluation matrix of each sub-factor, $R_{i}(i=1,2,3,4)$, that $R_{1}$ represents the comprehensive evaluation matrix of sub-factors of "Design Topics", $R_{2}$ represents the comprehensive evaluation matrix of sub-factors of "Design Organization and Guidance", $R_{3}$ represents the comprehensive evaluation matrix of sub-factors of "Thesis Plea", $R_{4}$ represents the comprehensive evaluation matrix of "Design Effectiveness". 3) According to the weight distribution in the comparison matrix A, obtain the first-level fuzzy evaluation result vector of various sub-factors, $B_{i}(i=1,2,3,4)$, wherein中 $B_{i}=A_{i} \times R_{i}$, and conduct the normalization process to $B_{i}(i=1,2,3,4)$. Use $B_{i}(i=1,2,3)$ to construct the second-level evaluation matrix R, obtain the evaluation result matrix according to $B=A \times R$. 4) Determine the evaluation level of the teacher's practical teaching [7]. 


\section{Conclusion}

The vocational practical teaching evaluation is a very complex issue and it will meet much more difficulties when operating under the university-enterprise cooperation mode, the evaluation is one of the problems that vocational colleges are researching jointly. The author in the paper has constructed the practical teaching evaluation index system under the university-enterprise cooperation mode, calculated the weights of each index with AHP and applied the comprehensive fuzzy theory to conclude decision. The cases showed that the system and the calculation process have the effectiveness and feasibility.

\section{Acknowledgements}

This work was financially supported by the project of Guangdong higher vocational education research association (No.GDGZ14Y07), and by Guangdong Province University Outstanding Young Teachers' Training Program (No.Yq2013201), and by Guangdong province science and technology plan projects (No.2014A010103002), and by the project of China higher vocational education research association (No.GZYLX1213279), and by the College students off-campus practice teaching base construction projects of Guangdong Province in 2014, and by the Key Teaching Reform Project of Dongguan Polytechnic (JGXM2014020), and by the fund project of Dongguan Polytechnic (No.2014a06, No.2014d16, No.2014a07).

\section{References}

[1] Nora Muda, Humaida Banu Samsudin. Students Perspective on Lecturer Characteristic for Effective Teaching. Procedia-Social and Behavioral Sciences, 59(17), pp. 535-540, 2012.

[2] Shin-ichi Ohnishi, Takahiro Yamanoi. On Fuzzy Priority Weights of AHP for Double Inner Dependence Structure. Procedia Computer Science, 35, pp. 1003-1012, 2014.

[3] Ru-Jen Chao, Yueh-Hsiang Chen. Evaluation of the criteria and effectiveness of distance elearning with consistent fuzzy preference relations. Expert Systems with Applications, 36(7), pp. 10657-10662, 2009.

[4] Hosang Jung. A fuzzy AHP-GP approach for integrated production-planning considering manufacturing partners. Expert Systems with Applications, 38(5), pp. 5833-5840, 2011.

[5] Hua Zhang, haiwei Mu, Yong Zhang, Jian Han, 2014, Design of On-line Measurement Module of Internal Resistance for Lithium-ion Battery, Journal of applied science and engineering innovation, Vol.1 No.3, pp.228-231.

[6] Chih-Hsuan Wang, Juite Wang. Combining fuzzy AHP and fuzzy Kano to optimize product varieties for smart cameras: A zero-one integer programming perspective. Applied Soft Computing, 22, pp. 410-416,2014.

[7] Yi-Hui Chiang. Using a combined AHP and PLS path modelling on blog site evaluation in Taiwan.Computers in Human Behavior, 29(4), pp. 1325-1333, 2013.

[8] Jingfei Yu, Li Wang, Xiuling Gong. Study on the Status Evaluation of Urban Road Intersections Traffic Congestion Base on AHP-TOPSIS Modal. Procedia-Social and Behavioral Sciences, 96(6), pp. 609-616, 2013. 